\title{
Palmer, K. T., Brown, I., and Hobson, J. (eds): Fitness for Work: The Medical Aspects (fifth edition)
}

\author{
Oxford University Press, Oxford, 2013, 736 pp, \$89.95 (softbound)
}

\author{
Bruce A. Barron
}

Published online: 3 June 2014

(C) Springer Science+Business Media New York 2014

The fifth edition of Fitness for Work: The Medical Aspects was recently published by Oxford University Press. Similar to its previous four editions, this text addressed a wide variety of fitness for work issues commonly encountered in the workplace. Primary, secondary, and tertiary prevention of worker illness, injury, and impairment were once again incorporated into this publication. Previously identified as an authoritative book on fitness for work, the fifth edition was endorsed by the Faculty of Occupational Medicine of the Royal College of Physicians of London.

As in previous editions, most of the chapters were coauthored by a subject matter expert and an occupational medicine physician. The body of the text and chapters were logically sequenced and well-organized. New chapters added to this edition included sickness absence management, fitness for work following surgery and after critical illness, and cancer survivorship. The remaining chapters were revised and updated by respected experts in the field.

The first five chapters introduced a general framework for assessing fitness for duty, legal aspects of fitness for duty, disability law, ethics, and restoring fitness for work. The chapters involving legalities had limited value since they were based on United Kingdom (UK) law and not applicable to those practicing in other countries. The clinical chapters covered all major organ systems in addi-

B. A. Barron ( $\square)$

Division of Occupational and Environmental Medicine,

University of Rochester School of Medicine and Dentistry,

Rochester, NY, USA

e-mail: bruce_barron@urmc.rochester.edu tion to special topics such as rehabilitation, women at work, human immunodeficiency virus, substance abuse, medication and health, older workers, ill health retirement, management and prevention of medical absences, health screening, and health promotion. Each clinical chapter started with a general introduction followed by more indepth analysis of specific medical conditions. The clinical reviews focused not only on the impact of an employee's health on work ability, but also the impact of work on employee's health. Strategies for evidence-based medical treatment and rehabilitation as well as recommendations for timely and safe return to work after injury and illness were proffered.

Similar to previous editions, Fitness for Work: The Medical Aspects provided a comprehensive and authoritative review on the subject of fitness for work. The chapters were logically sequenced and organized for easy use and reference. Although the book succinctly summarized a large number of clinical conditions, it was well referenced and included links to other resources such as additional references and subject matter experts. The information provided by the authors could be used to optimize employee health, performance, and productivity while minimizing the effects of impairment and disability. This new edition of Fitness for Work: The Medical Aspects should be of interest and value to a broad cross section of occupational health professionals such as occupational medicine physicians, physical medicine and rehabilitation specialists, employee health and wellness professionals, disability case managers, safety professionals, human resource professionals, and others. Future editions of Fitness for Work: The Medical Aspects should consider reducing or eliminating the chapters based on UK law to make it more appealing to its international readership. 